\title{
Evaluation of serum paraoxonase, 1 and its association with serum cholinesterase as a cause of congenital anomalies
}

\author{
Abhra Ghosh ${ }^{1 *}$, Jagriti Bhardwaj², Robin Singh ${ }^{3}$, Divya Baruhee ${ }^{2}$
}

\begin{abstract}
${ }^{1}$ Department of Biochemistry, Dayanand Medical College and Hospital, Ludhiana, Punjab, India
${ }^{2}$ Department of Obstetrics and Gynecology, ESIC Basaidarapur, New Delhi, India

${ }^{3}$ Department of Oncology, Dayanand Medical College and Hospital, Ludhiana, Punjab, India
\end{abstract}

Received: 08 June 2020

Accepted: 08 July 2020

\author{
*Correspondence: \\ Dr. Abhra Ghosh, \\ E-mail: abhraghoshcmc08@gmail.com
}

Copyright: () the author(s), publisher and licensee Medip Academy. This is an open-access article distributed under the terms of the Creative Commons Attribution Non-Commercial License, which permits unrestricted non-commercial use, distribution, and reproduction in any medium, provided the original work is properly cited.

\begin{abstract}
Background: Birth defects are conditions of prenatal origin that are present at birth, potentially impacting an infant's health, development, and/or survival. Several environmental toxins affect the growth of the fetus during the intrauterine period by affecting various cellular components. Pesticides and industrial chemicals are known toxins that can hinder the developmental process. In this study, authors are evaluating the relation of cholinesterase and paraoxonase-1 with visible congenital anomalies.

Methods: Sixty babies delivered in the labor room were selected for the study. They were divided into two groups. Thirty newborns with visible congenital anomalies were included in Group I. Only babies with visible congenital anomalies were taken as inclusion criteria for this group. This group was compared with Group II, which were taken as controls and consisted of 30 healthy newborns without any congenital anomalies. Serum cholinesterase and serum paraoxonase-1 were estimated and statistical tests were applied.

Results: Serum cholinesterase and serum paraoxonase-1 were significantly low in the babies with visible congenital anomalies. Serum cholinesterase levels showed a statistically significant positive correlation with serum paraoxonase 1 level in both the groups.

Conclusions: Decrease in acetylcholinesterase by various environmental toxins and the associated decrease in serum paraoxonase level imposes significant oxidant stress and the resultant risk of developing congenital anomalies.
\end{abstract}

Keywords: Congenital anomalies, Cholinesterase, Paraoxonase 1

\section{INTRODUCTION}

Congenital anomalies, also commonly referred to as birth defects, are conditions of prenatal origin that are present at birth, potentially impacting an infant's health, development, and/or survival. On a global scale, an estimated 303000 new-borns die annually before reaching 4 weeks of age due to congenital anomalies and associated complications with neural tube defects being one of the most serious and most common of these anomalies. ${ }^{1}$ The prevalence of birth defects in India is 6$7 \%$ which translates to around 1.7 million birth defects annually. The common birth defects include congenital heart disease (8-10 per 1000 live births), congenital deafness (5.6-10 per 1000 live births), and neural tube defects (4-11.4 per 1000 live births). ${ }^{2}$

The causes of congenital anomalies are multifarious, with many anomalies remaining of undetermined etiology. Structural anomalies are often due to errors in embryogenesis occurring at critical periods of fetal development. The first trimester (gestational age 1-12 weeks) is generally considered as the highest risk period. Medications, infectious agents, and environmental toxins have all been implicated as functional teratogens and can also disrupt fetal development and increase the risk for 
one or more congenital abnormalities. ${ }^{3}$ Some structural and functional defects may also be attributed to underlying genetic defects or chromosomal abnormalities. These defects may be due to one or both parents being genetic carriers, one or both parents sharing the disease state, or the occurrence of de novo mutations. ${ }^{4}$

Ill-health effects of environmental pollutants include adverse outcomes of pregnancy: low birth weight, stillbirth, neonatal death, and congenital anomalies. Organophosphate (OP) or carbamate esters are used as pesticides, insecticides, chemical warfare agents, and drugs for the treatment of medical disorders such as glaucoma, parasite infections, and Alzheimer's disease and are potent anticholinesterase. Acetylcholine (ACh) and other neurotransmitters play unique trophic roles in the development of the CNS. Inhibition of acetylcholinesterase (AChE) by organophosphates (OPs) can result in the accumulation of acetylcholine, which may then conceivably disturb this development. Maternal serum acetylcholinesterase levels have been reported to be low and independent of gestational age between 1420 weeks in a sample of normal pregnancies with normal alpha-fetoprotein levels. Raised levels of maternal serum secretory acetylcholinesterase were found in $100 \%$ of pregnancies involving spina bifida and three of four anencephalic compared with raised alpha-fetoprotein levels found in $88 \%$ and $100 \%$ of the same samples. 5,6

The paraoxonases comprise three isoforms (PON1, PON2, and PON3) that attenuate oxidant stress; among these, only paraoxonase 1 (PON1) hydrolyzes organophosphates. Paraoxonase 1 (PON1) is also a major anti-atherosclerotic component of high-density lipoprotein (HDL). Paraoxonase 1 (PON1) is the enzyme responsible for the deactivation of organophosphates (OPs) in the central nervous system. Pathological conditions such as diabetes, Alzheimer's disease, and cardiovascular disease have also been linked to reduced paraoxonase 1 (PON1) activity. Paraoxonase 1 (PON1) polymorphisms have been reported to be relevant risk factors for having offspring affected with spina bifida in the population from southeast Mexico. ${ }^{7}$ Serum paraoxonase 1 (PON1) levels and activity vary widely among different ethnic populations and its role in organophosphate (OP) toxicity and congenital anomalies are required to be explored. ${ }^{8}$

However, no such studies are available in the Indian context, especially in Haryana. Hence the present study is proposed to evaluate the association of serum cholinesterase levels and paraoxonase 1 with congenital anomalies in the Indian population to collect baseline data so that preventive and diagnostic measures can be planned in environmental health studies for Indian children.

\section{METHODS}

The present study was conducted in the Department of Biochemistry in collaboration with the Department of
Obstetrics \& Gynaecology, Pandit Bhagwat Dayal Sharma PGIMS, Rohtak. Sixty babies delivered in the labor room were selected for the study. They were divided into two groups. Thirty newborns with visible congenital anomalies were included in Group I. Only babies with visible congenital anomalies were taken as inclusion criteria for this group. This group was compared with Group II, which were taken as controls and comprised of 30 healthy newborns without any congenital anomalies.

All the patients were subjected to a detailed history and clinical examination as per proforma attached. Ten $\mathrm{mL}$ cord blood was collected from the placental end of the umbilical cord immediately after delivery of the baby. The serum was separated by centrifugation and routine investigations were done on the same day and serum for special investigations was preserved at $-20^{\circ} \mathrm{C}$ till analysis.

Serum cholinesterase levels were measured in Cobas c311 using a kit from Roche diagnostics. Paraoxonase 1 levels in serum were analyzed by using double-antibody sandwich enzyme-linked immunosorbent assay kits (Elabscience kit).

\section{Statistical analysis}

Results were analyzed by SPSS version 23 was used for statistical analysis and expressed as mean \pm SD and unpaired ' $\mathrm{t}$ ' test and Pearson correlation test was applied. Data was considered to be significant if $\mathrm{p}<0.05$.

\section{RESULTS}

Cleft lip ( $n=7)$ was the most common congenital anomaly in the present study, while CTEV was the second most common $(n=6)$ anomaly. Hypospadias, polydactyly, spina bifida showed similar distribution with 3 cases each; limb defect (DDH) was seen only in two cases. Omphalocele, anencephaly, gastroschisis, encephalocele, cleft palate, and imperforate anus were seen in 1 case each.

Table 1: Comparison of birth weight and gestational age.

\begin{tabular}{|lll|}
\hline Parameter & Group I & Group II \\
\hline Birth weight $(\mathrm{kg})$ & $2.44 \pm 0.47$ & $2.56 \pm 0.42$ \\
\hline Range & $(1.37-3)$ & $(1.6-3.3)$ \\
\hline Gestational age (weeks) & $36.10 \pm 1.99 *$ & $36.27 \pm 1.68$ \\
\hline Range & $(31-39)$ & $(33-39)$ \\
\hline *p $>0.05$ when compared to Group II. &
\end{tabular}

Birth weight was comparable in both groups, but it was not statistically significant, gestational age was lower in Group I as compared to Group II, but it was not statistically significant (Table 1).

Serum paraoxonase 1 level was significantly decreased in new-borns with congenital anomalies (Group I) as compared to new-borns without congenital anomalies $(\mathrm{p}<0.001(0.000)$, Table 2). 
Table 2: Serum paraoxonase 1 levels in both groups (mean \pm SD, $\mathrm{ng} / \mathrm{mL}$ ).

\begin{tabular}{|c|c|c|}
\hline Parameter & Group I & Group II \\
\hline $\begin{array}{l}\text { Serum paraoxanase - } \\
1(\mathrm{ng} / \mathrm{mL})\end{array}$ & $5.068 \pm 1.750 * *$ & $7.531 \pm 1.637$ \\
\hline Range & $1.966-7.390$ & $3.137-9.742$ \\
\hline
\end{tabular}

Serum cholinesterase levels were significantly decreased in new-borns with congenital anomalies (Group I) as compared to new-borns without congenital anomalies (Group II) ((p<0.001 (0.0002), Table 3).
Serum cholinesterase levels showed a statistically significant positive correlation with serum paraoxonase 1 level in both the groups $(\mathrm{r}=0.772$ versus 0.967 , $\mathrm{p}<0.001(0.000)$; Table 4).

Table 3: Serum cholinesterase levels in both groups (mean \pm SD, U/L).

\begin{tabular}{|lll|}
\hline Parameter & Group I & Group II \\
\hline Serum cholinesterase & $3575.90 \pm 1$ & $4784.33 \pm 12$ \\
(U/L) & $200.65 * * *$ & 65.04 \\
\hline Range & $2089-6786$ & $1203-7403$ \\
\hline$* * * p<0.001$ when compared to Group II.
\end{tabular}

$* * * \mathrm{p}<0.001$ when compared to Group II.

Table 4: Correlation of serum cholinesterase levels and serum paraoxonase 1 levels two groups (mean \pm SD).

\begin{tabular}{|c|c|c|c|c|}
\hline Parameter & Group I & r value & Group II & r value \\
\hline Serum cholinesterase (U/L) & $3575.90 \pm 1200.65$ & \multirow{2}{*}{$\begin{array}{l}r=0.772 \\
p<0.001(0.000)\end{array}$} & $4784.33 \pm 1265.04$ & \multirow{2}{*}{$\begin{array}{l}r=0.967 \\
p<0.001(0.000)\end{array}$} \\
\hline Serum paraoxanase (ng/mL) & $5.068 \pm 1.750$ & & $7.531 \pm 1.637$ & \\
\hline
\end{tabular}

Table 5: District wise distribution of serum fluoride, cholinesterase, paraoxonase 1 levels in Group I (mean \pm SD, $\mathrm{mg} / \mathrm{L}, \mathrm{U} / \mathrm{L}, \mathrm{ng} / \mathrm{mL})$.

\begin{tabular}{|lll|}
\hline District (no. of cases) & Serum cholinesterase (U/L) & Serum PON1 (ng/L) \\
\hline Sonipat (7) & $3081.71 \pm 795.48$ & $4.475 \pm 1.928$ \\
\hline Panipat (6) & $2815.33 \pm 293.53$ & $4.138 \pm 1.690$ \\
\hline Bhawani (5) & $3851.40 \pm 1896.24$ & $5.350 \pm 1.396$ \\
\hline Jind (5) & $3696.40 \pm 1389.06$ & $4.377 \pm 2.253$ \\
\hline Rohtak (3) & $4135.33 \pm 111.51$ & $6.330 \pm 0.070$ \\
\hline Hisar (3) & $5369.37 \pm 1583.55$ & $6.710 \pm 0.755$ \\
\hline Jhajjar (1) & $3569.00 \pm 0.000$ & $6.195 \pm 0.000$ \\
\hline
\end{tabular}

Serum cholinesterase levels in Group I was lowest in babies from Panipat district followed by Sonepat district. Babies from Hisar had the highest serum cholinesterase levels in Group I. Serum paraoxonase - 1 level in Group I were lowest in babies from Panipat district followed by babies from Jind district. Babies from Hisar had the highest serum paraoxonase - 1 level in Group I (Table 5).

\section{DISCUSSION}

Cholinesterase (ChE) is found in the liver, pancreas, heart, white matter of the brain, and serum. Plasma ChE is produced by the liver in man and animals. Studies have shown that decreased cholinesterase levels in cord blood can be a marker for congenital anomalies. ${ }^{9,10}$ Whereas in a study by Elejalde et al showed that congenital anomalies produced elevated levels of pseudocholinesterase (PChE) in amniotic fluid. ${ }^{11}$

Few studies have shown that exposure to a higher but sub-toxic level of pesticides causes an increase in BuChE (butyrylcholinesterase) levels. This paradoxical effect was attributed to enhanced BuChE synthesis as a natural protective mechanism against sub-toxic pesticide exposure. $^{12}$ In this study, lower birth weight and gestational age can be seen in newborns with congenital anomalies along with a decrease in serum cholinesterase levels (Table 1). A study by Farahat et al reported that similar findings in case of organophosphorus exposure. ${ }^{13}$

Paraoxonase 1 plays a major role in hydrolyzing organophosphate esters, carbamate pesticides, nerve agents, oxidized lipids, and pharmaceutical drugs. PON1 is considered to be an important biomarker of susceptibility towards toxic agents especially OP pesticides. Long term exposures to pesticides decrease PON1 activity and butyrylcholinesterase activity in industrial workers.

In the present study, serum paraoxonase 1 level was significantly decreased in newborns with congenital anomalies (Group I) as compared to newborns without congenital anomalies (Group II, Table 2).

In the present study, serum cholinesterase levels showed a positive correlation with serum paraoxonase- 1 levels in 
both groups, which is statistically significant in both groups (Table 4). The mode of action of different pesticides is through inhibition of acetylcholinesterase activity. In pesticide poisoning, cholinesterase activity is inhibited. ${ }^{14}$ Paraoxonase 1 detoxifies most of the organophosphorus compounds. Relationship between cholinesterase and paraoxonase 1 and their association with organophosphorus induced health outcomes have been suggested in some studies. ${ }^{15,16}$

In the present study, babies with anencephaly $(n=1)$, omphalocele $(n=1)$, encephalocele $(n=1)$ and hypospadias $(n=3)$ had significantly lower levels of serum paraoxonase 1 compared to other congenital anomalies in Group I. Commonest anomalies seen in this study - cleft lip, CTEV has no significant difference in PON1 levels in comparison to the control group. In a study by Targut et al also, no statistical difference in paraoxonase 1 enzyme activity between congenital anomalies like cleft lip/cleft palate patients and control group was seen. They also found that there is no significant difference present in paraoxonase 1 enzyme activity in the parents of both groups. ${ }^{17}$

Several studies have shown that PON1 has a major role in the detoxification of OP compounds. Araoud et al showed that PON1 activity in workers exposed to pesticides was positively correlated with serum BChE activity. ${ }^{18}$ Though this correlation was lower in subjects who are acutely exposed than in subjects chronically exposed to organophosphates. It has been found that the administration of PON1 abolished cholinergic signs and significantly protected it from AchE inhibition. However, Hernandez et al did not find any correlation between AChE and PON1 activities in greenhouse workers exposed to pesticides. ${ }^{19}$ It has been found that susceptible individuals who have been exposed to OPs and have inheritably low PON1 activity caused increased oxidative damage to highly sensitive AChE. This also leads to excessive acetylcholine in the dopaminergic system causing symptoms of parkinsonism. ${ }^{18}$

A positive correlation between PON1 and ChE has been reported in the serum of pesticide poisoning individuals suggesting that patients with higher PON1 activity may detoxify the pesticide poisoning more effectively. Thus, PON1 can act as a potent biomarker for diagnosis and prognosis of OP poisoning. ${ }^{20}$

Serum cholinesterase levels in Group I was lowest in babies from Panipat district followed by Sonepat district. Babies from Hisar had the highest serum cholinesterase levels in Group I (Table 5) in the present study.

Reports have been published that rivers flowing through Haryana are heavily contaminated by domestic and industrial wastes along with agricultural runoff and excessive amounts of pesticides. ${ }^{21}$ Contaminated water from rivers is one of the important sources of drinking water in the population of Haryana. Its contamination with pesticides can cause various harmful effects. ${ }^{22}$

In the present study, serum paraoxonase 1 level in Group I was lowest in babies from Panipat district followed by babies from Jind district. Babies from Hisar had the highest serum paraoxonase - 1 level in Group I (Table 5).

It has been documented low ChE levels inhibit PON1 by inactivation of the enzyme. Since babies from Panipat district have lowest ChE levels, these factors could inactivate PON1 resulting in low levels of the enzyme. It may be appreciated here that the Panipat district of Haryana state has the maximum number of factories and industries, as well as agricultural areas.

Acute toxicological effects of OP pesticides are a result of inhibition of AChE in the nervous system and chronic effects are not well documented. However, several reports indicate that certain birth outcomes (e.g., decreased gestational age, decreased birth weight) may be associated with environmental exposure to OP pesticides. PON1 has an extensive role in preventing the accumulation of lipoperoxidase in LDL. Polymorphism of PON1 has been reported to be associated with miscarriage, Parkinson's disease, atherosclerosis, cardiovascular disease, and neurodevelopment. There is an association between genetic polymorphism of PON1 with DNA damage in occupational workers exposed to OPs. $^{23}$

Serum PON1 represents one of the first lines of defense available for any absorbed organophosphorus compounds. Other defenses in blood against OPs include anticholinesterases such as serum butyrylcholinesterase or erythrocyte cholinesterase that are persistently inhibited by organophosphorus compounds and are saturable.

\section{CONCLUSION}

Every life matters! The need to prevent women's reproductive ill health, the need to prevent the death of infant, is the need for primary prevention. The environment and surroundings play a vital role and have a direct effect on public health. An unregulated increase in pesticide use and other industrial toxins has detrimental effects, especially on pregnant women. Inhibition of acetylcholinesterase by organophosphates and the associated decrease in serum paraoxonase level imposes significant oxidant stress and the resultant risk of developing congenital anomalies.

\section{ACKNOWLEDGMENTS}

Authors would like to thank guides Dr. Simmi Kharb, Prof and Head, department of biochemistry and Dr. Smiti Nanda, Prof and Head, department of obstetrics and gynecology, PGIMS, Rohtak for their continuous support and guidance. 
Funding: No funding sources

Conflict of interest: None declared

Ethical approval: The study was approved by the Institutional Ethics Committee

\section{REFERENCES}

1. Impact: Congenital anomalies. Available at: https://www.who.int/health-topics/ congenitalanomalies\#tab=tab_3. Accessed on $8^{\text {th }}$ June 2020.

2. Congenital anomalies (birth defects). Available at: https://www.nhp.gov.in/ disease/ gynaecology-andobstetrics/congenital-anomalies-birth-defects. Accessed at $8^{\text {th }}$ June 2020 .

3. Khoury MJ. Epidemiology of birth defects. Epidemiol Rev. 1989;11:244-8.

4. Wellesley D, Boyd P, Dolk H, Pattenden S. An aetiological classification of birth defects for epidemiological research. J Med Genet. 2005;42:54-7.

5. Brennand DM, Jehanli AM, Wood PJ, Smith JL. Raised levels of maternal serum secretory acetylcholinesterase may be indicative of fetal neural tube defects in early pregnancy. Acta Obstet Gynecol Scand. 1998;77:8-13.

6. Loft AG, Høgdall E, Larsen SO, Nørgaard-Pedersen B. A comparison of amniotic fluid alpha-fetoprotein and acetylcholinesterase in the prenatal diagnosis of open neural tube defects and anterior abdominal wall defects. Prenat Diagn. 1993;13:93-109.

7. Engel SM, Berkowitz GS, Barr DB, Teitelbaum SL, Siskind J, Meisel SJ et al. Prenatal organophosphate metabolite and organochlorine levels and performance on the Brazelton Neonatal Behavioral Assessment Scale in a multi-ethnic pregnancy cohort. Am J Epidemiol. 2007; 165:1397-404.

8. Gonzalez HL, Martín CFR, Luna RM, Canto HJ, Pinto ED, Perez HN, et al. Paraoxonase 1 polymorphisms and haplotypes and the risk for having offspring affected with spina bifida in Southeast Mexico. Birth Defects Res A Clin Mol Teratol. 2010;88:987-94.

9. Roy PS, Ghosh A. Cholinesterase as marker of congenital anomalies. Int J Sci Res. 2018;7(9):19-20.

10. Venkataraman B, Iyer G, Narayanan R. Erythrocyte and plasma cholinesterase activity in normal pregnancy. Indian J Physiol. 1990;34:26-8.

11. Elejalde BR, Peck G, Elejalde MM de. Determination of cholinesterase and acetylcholinesterase in amniotic fluid. Clin Genet. 2008;293:196-203.

12. Lozano-Paniagua D, Gómez-Martín A, Gil F, Parrón T, Alarcón R, Requena M, et al. Activity and determinants of cholinesterases and paraoxonase-1 in blood of workers exposed to non-cholinesterase inhibiting pesticides. Chem Biol Interact. 2016;259:160-7.

13. Farahat T, Shaheen HM, Sanad Z, Farag NA. Organophosphate pesticide exposure during pregnancy and adverse perinatal outcome. J Womens Health Care. 2016;5:336.

14. Thiermann H, Kehe K, Steinritz D, Mikler J, Hill I, Zilker T, et al. Red blood cell acetylcholinesterase and plasma butyrylcholinesterase status: important indicators for the treatment of patients poisoned by organophosphorus compounds. Arh Hig Rada Toksikol. 2007;58:359-66.

15. Bryk B, BenMoyal-Segal L, POdoly E, Livanh O, Eisenkraft A, Luria S, et al. Inherited and acquired interactions between AChE and PON1 polymorphisms modulate plasma acetylcholinesterase and paraoxonase activities. J Neurochem. 2005:92:1216-27.

16. Hofmann JN, Keifer MC, Furlong CE, De Roos AJ, Farin FM, Fenske RA, et al. Serum Cholinesterase inhibition in relation to paraoxonase-1 (PON-1) status among organophosphate-exposed agricultural pesticide handlers. Environ Health Perspect. 2009:117:1402-8.

17. Turgut G, Özcan A, Çakmak E, Baş L, Tatlidede S, Öztürk O, et al. Paraoxonase-1 192 enzyme polymorphism in non-syndromic clefting: In patients and parents. J Cell Mol Biol. 2008:67.

18. Araoud M, Neffeti F, Douki W, Najjar MF, Kenani A. Paraoxonase 1 correlates with butyrylcholinesterase and gamma glutamyl transferase in workers chronically exposed to pesticides. J Occup Health. 2010;52:383-8.

19. Hernandez AF, Gomez MA, Pena G, Gil F, Rodrigo L, Villanueva E, Pla A. Effect of longterm exposure to pesticides on plasma esterases from plastic greenhouse workers. J Toxicol Environ Health. 2004;67:1095-108.

20. Richard SA, Frank EA, D'Souza CJ. Correlation between cholinesterase and paraoxonase 1 activities: case series of pesticide poisoning subjects. Bioimpacts. 2013;3:119.

21. Bhattacharya N, Phillip GS (eds.). Human fetal growth and development: first and second trimesters. Switzerland: Springer; 2016:94.

22. Kaushik A, Sharma HR, Jain S, Dawra J, Kaushik CP. Pesticide pollution of river Ghaggar in Haryana, India. Environ Monit Assess. 2010;160:61-9.

23. Singh S, Kumar V, Singh P, Thakur S, Banerjee BD, Rautela RS, et al. Genetic polymorphisms of GSTM1, GSTT1 and GSTP1 and susceptibility to DNA damage in workers occupationally exposed to organophosphate pesticides. Mutat Res Genet Toxicol Environ Mutagen. 2011;725:36-42.

Cite this article as: Ghosh A, Bhardwaj J, Singh R, Baruhee D. Evaluation of serum paraoxonase, 1 and its association with serum cholinesterase as a cause of congenital anomalies. Int J Reprod Contracept Obstet Gynecol 2020;9:3388-92. 